\title{
The COVID-19 Epidemic in Rural U.S. Counties
}

\author{
Philip N. Cohen ${ }^{1,2 *}$
}

${ }^{1}$ University of Maryland, College Park, MD 20742, USA

${ }^{1}$ Maryland Population Research Center, College Park, MD 20742, USA

*Corresponding Author: pnc@umd.edu

Citation: Cohen, P. N. (2020). The COVID-19 Epidemic in Rural U.S. Counties. European Journal of Environment and Public Health, 4(2), em0050. https://doi.org/10.29333/ejeph/8331

\section{ARTICLE INFO}

Received: 18 Apr. 2020

Accepted: 22 May 2020

\begin{abstract}
Having first reached epidemic proportions in coastal metropolitan areas, COVID-19 has spread around the country. Reported case rates vary across counties from zero to 126 per thousand population (around a state prison in the rural county of Trousdale, Tennessee). Overall, rural counties are underrepresented relative to their share of the population, but a growing proportion of all daily cases and deaths have been reported in rural counties. This analysis uses daily reports for all counties to present the trends and distribution of COVID-19 cases and deaths in rural counties, from late March to May 21, 2020. I describe the relationship between population density and case rates in rural and non-rural counties. Then I focus on noteworthy outbreaks linked to prisons, meat and poultry plants, and nursing homes, many of which are linked to high concentrations of Hispanic, American Indian, and Black populations. The growing epidemic in rural counties is apparently driven by outbreaks concentrated in these institutional settings, which are conducive to transmission. The impact of the epidemic in rural areas may be heightened due to their weaker health infrastructure and more vulnerable populations, especially due to age, socioeconomic status, and health conditions. As a result, the epidemic may contribute to the ongoing decline of health, economic, and social conditions in rural areas.
\end{abstract}

Keywords: COVID-19, rural health, health disparities, race/ethnicity

\section{INTRODUCTION}

After spreading around the country for at least four months (CDC, 2020), COVID-19 cases remain unevenly distributed geographically, with 193 of the 3,143 counties reporting no cases, the average county reporting 2.1 cases per thousand, and the maximum as high as 125 per thousand - in Trousdale County, Tennessee, where an outbreak at the state prison drove the epidemic (Bosman et al., 2020b). Although the U.S. epidemic has had its greatest impact in coastal urban areas, it is increasingly reaching into rural areas. In this paper I describe the spread of reported COVID-19 cases and deaths into rural counties of the United States, with attention to race/ethnic composition, population density, and institutional factors.

The COVID-19's effect on rural areas may exacerbate existing health disparities in the U.S. (Dorn et al., 2020). Although we would expect lower transmission rates in rural areas, because of lower population density, there also may be higher rates of serious complications and death because of their older age profile, poorer health status, and degraded health care infrastructure (Ameh et al., 2020; Cafer and Rosenthal, 2020). The context of urban-rural health disparity, and disparities within rural areas, are important to understand the impact of the epidemic in rural areas.

Health disparities between rural and urban areas in the U.S. are wide and growing wider (James and Cossman, 2017; Singh et al., 2017). Rural residents are older, have lower average educational attainment, and have lower incomes, than urban residents. And there are substantial disparities within the rural population, with Black, Hispanic, and American Indian populations having worse social and economic conditions than non-Hispanic Whites. Concurrently, rural ethnic minorities are more likely to report poorer health status, lack of access to medical care, and higher prevalence of chronic health problems (James et al., 2017). Rural residents also have less access to reliable health information, both from service providers and from media sources (Chen et al., 2019), and are less likely to use health information technology (Greenberg et al., 2018). These disadvantages in U.S. rural areas suggest the possibility of serious impact of the COVID-19 epidemic, despite the advantage of lower population density for transmission rates. And within rural areas, we need to assess disparate impacts by race/ethnicity and social class.

In addition, three specific institutional settings in which the epidemic has surged in the rural U.S. deserve special attention: meat and poultry processing plants, prisons, and 
nursing homes and long-term care facilities. By April 28, the Centers for Disease Control and Prevention (CDC) reported results from a voluntary survey of correctional and detention facilities, which yielded responses from 37 jurisdictions. In these facilities, there were about 4,900 COVID-19 confirmed cases among prisoners, as well as 2,800 among their staffs, leading to more than 100 deaths. The outbreaks are apparently fueled by crowding, close quarters, lack of testing and medical isolation facilities, turnover among prisoners, and continuous entry and exit by staff (Wallace, 2020). Some of the biggest prison outbreaks of COVID-19 have been in rural areas, including the one in Trousdale County, Tennessee.

By April 27, 2020, CDC reported almost 5,000 cases of COVID-19 at 115 meat and poultry processing facilities in 19 states, affecting plants that employ more than one-fifth of the industry. At the extreme, one plant reported an 18 percent infection rate among its workers (Dyal, 2020). CDC suggested that the close proximity, physical exertion, fast work pace, and lack of adequate disinfecting were likely contributors to the outbreaks. Workers have reported unsafe working conditions and failure to implement steps need to reduce transmission in plants (Laughland and Holpuch, 2020). At the end of April, President Trump ordered meat processing plants to remain open (White House, 2020), even as the union representing the most workers in the industry, the United Food and Commercial Workers International Union, called for heightened safety enforcement and testing in the plants nationwide (UFCW, 2020). Many affected meat and poultry processing facilities are in rural areas, as shown in the examples below.

The CDC has not yet reported on the epidemic's impact on nursing homes, but media aggregations of state health authorities indicate more than 20,000 people have died in nursing homes nationally (Into America, 2020). Again, the rural/urban distribution of these cases is not yet known, but some nursing home outbreaks are apparent in the county case reports I provide below. In addition to these settings, early rural outbreaks apparently stemmed from tourism or seasonal housing (Carson, 2020). However, those outbreaks were overtaken by larger outbreaks in the institutional settings described here.

At this point we do not yet have the data necessary to parse the relative contribution of each of these settings to the overall COVID-19 epidemic in rural areas. However, this descriptive review of the case and death data, with an informal survey of pubic reports, indicates the potential importance of these institutional settings.

The early months of the COVID-19 epidemic have revealed a disparate impact on Black, Hispanic, and American Indian communities (Almagro and Orane-Hutchinson, 2020; Dyer, 2020; Kovich, 2020; Solis et al., 2020). In some rural cases, there is likely an overlap between race/ethnic composition and the institutional factors described here. For example, the concentration of Black prisoners in rural prisons and Hispanic workers in meat processing plants. In the absence of the data necessary to draw these connections systematically, I use race/ethnic concentration to look for patterns across counties.

In the descriptive analysis that follows, I present the trends and distribution of COVID-19 cases and deaths in rural counties, from late March to May 21, 2020, the latest data available. I describe the relationship between population density and case rates in rural and non-rural counties. Then I focus on noteworthy outbreaks linked to prisons, meat plants, and nursing homes - and associated with high concentrations of Hispanic, American Indian, and Black populations.

\section{DATA AND MATERIALS}

COVID-19 data are drawn from the database maintained by the New York Times (2020), which is updated daily with reports from public health authorities around the country. The data reported at the county level used here include the number of new confirmed (or presumed) cases and deaths each day in each county. ${ }^{1}$ County population data, including race/ethnic composition, are 2018 estimates from the U.S. Census Bureau (2020). Rurality is drawn from the 2010 Decennial Census, from which the Census Bureau reported the percentage of each the population in each county that lived in a rural area (Ratcliffe et al., 2016). I follow the Bureau's categorization of counties as (1) completely rural (100 percent), (2) mostly rural (50-99.9 percent), and (3) mostly urban (less than 50 percent rural). In the text I refer to counties with 50 percent or more rural population as "rural." I calculate county population density as residents per square mile, using the Census Bureau's (2019) estimates of land area. ${ }^{2}$

Finally, for counties with large COVID-19 outbreaks, I used Internet searching, mostly relying on local or national news sources, to identify likely centers for the outbreak. Most of these are easily identified, as when the state authorities in Tennessee listed some 1300 cases over several days at the state prison in Trousdale County. I was unable to find a clearly identified source in only one prominent case: Sullivan County, NY, with about 1300 cases. In most rural counties with large outbreaks, local or national media have published news reports about the institutional settings where the outbreak began. This is much easier to identify than in urban areas, where there are many large institutions with overlapping population exposures. Nevertheless, these place notes remain informal identifiers of likely centers of the disease. Note also that the outbreaks in these counties, and the case counts I provide, are not limited to people within these institutions, as they also include people in the surrounding communities within each county.

The data for this paper is from publicly available sources. The code is written in Stata (using the maptile program for maps). The code is available here: https://osf.io/wd2n6/, including links to all data used.

\footnotetext{
${ }^{1}$ The New York Times created two aggregate counties, for New York City (combining the five borough-counties) and Kansas City, Missouri (where the portions of Cass, Clay, Jackson and Platte counties in the municipality of Kansas City are combined into one). Both of these are non-rural counties, so they have little effect on this analysis.

${ }^{2}$ Two counties, Oglala Lakota, SD, and the Kusilvak Census Area, AK, are not included in the Census file. I retrieved their land areas from Wikipedia.
} 
Table 1. COVID-19 cases and deaths, by county rurality: May 21, 2020

\begin{tabular}{cccccccc}
\hline & Counties & Cases & Deaths & Population & Cases per 1,000 & Deaths per 100,000 \\
\hline Completely rural & 704 & 13,559 & 369 & $5,293,130$ & 2.6 & 7.0 \\
\hline Mostly rural & 1,185 & 77,495 & 3,462 & $36,777,424$ & 2.1 & 9.4 \\
\hline Mostly urban & 1,255 & $1,480,249$ & 90,352 & $285,096,928$ & 5.2 & 31.7 \\
\hline Total & 3,144 & $1,571,303$ & 94,183 & $327,167,482$ & 4.8 & 28.8 \\
\hline
\end{tabular}

\section{A. Cases}

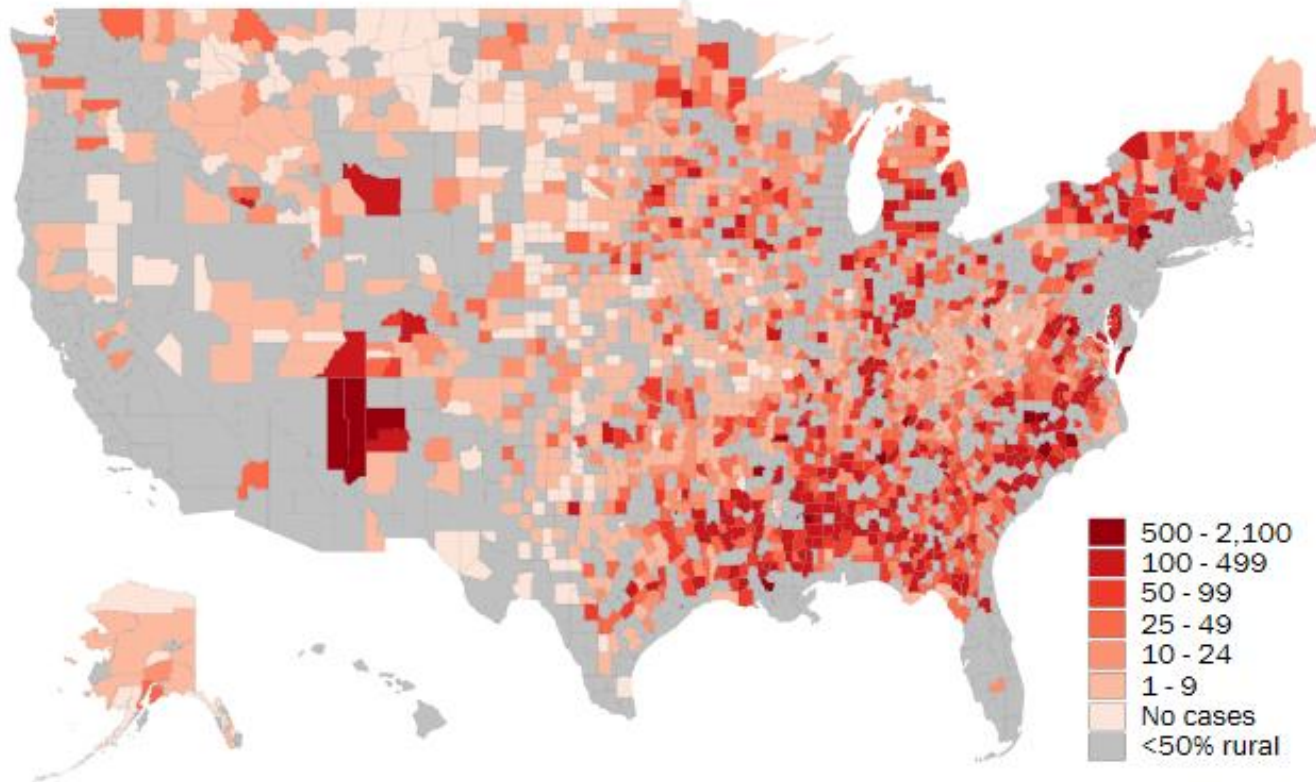

B. Cases per thousand population

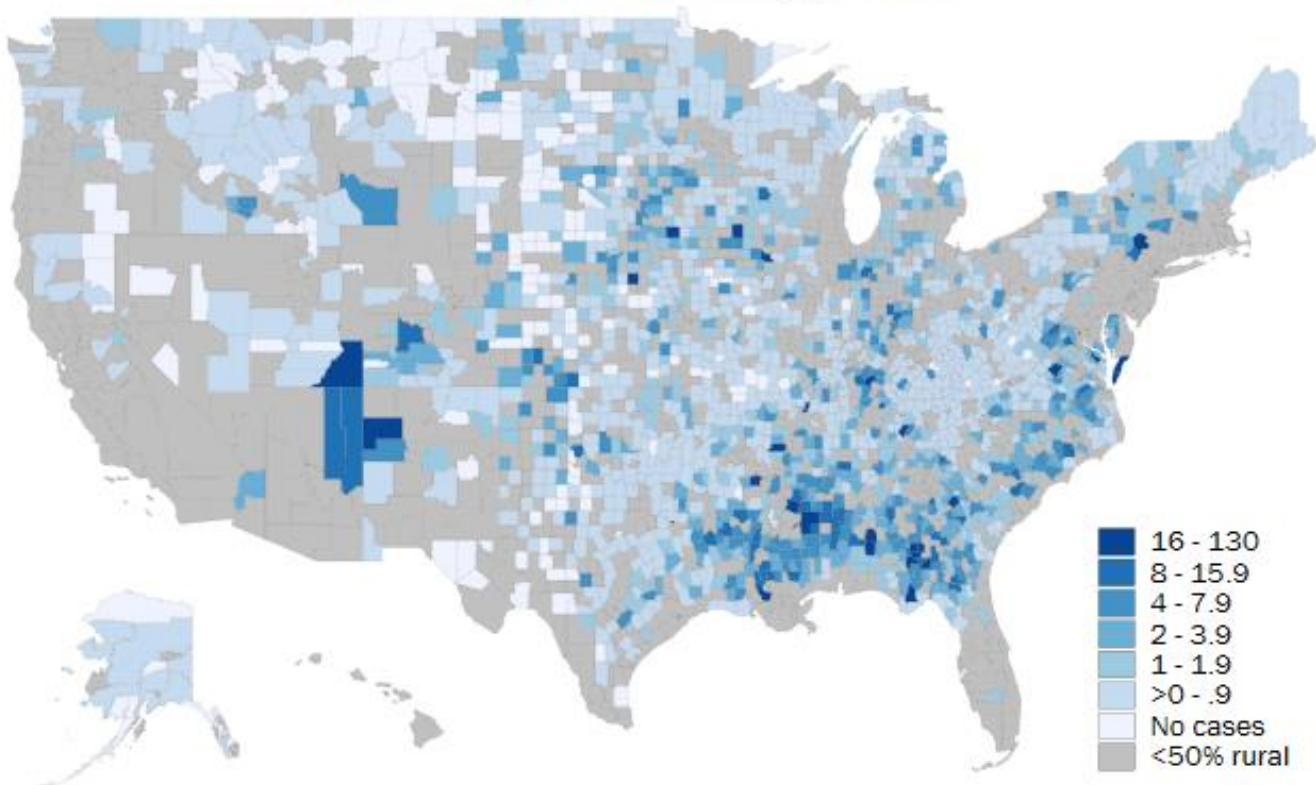

Figure 1. COVID cases in rural counties. Counties $>50 \%$ rural. Data as of May 21, 2020

\section{RESULTS}

By May 21, 2020, there were 1.6 million confirmed or presumed cases of COVID-19 in the U.S., and about 94,000 deaths (Table 1). Case and death rates were highest in urban counties (less than 50 percent rural). Rural counties recorded about 91,000 cases and about 3,800 deaths, the great majority of them in the mostly rural category (50-99 percent rural). From Table 1, we can see that the rural counties (both categories combined) account for 13 percent of the population, 6.2 percent of cases and 4.3 percent of deaths.

Figure 1 uses county maps to show the distribution of rural cases across the country. Panel A shows the count of cases reported by county, which ranges from 0 to 2,044. The greatest numbers are in the Southwest (American Indian reservation 

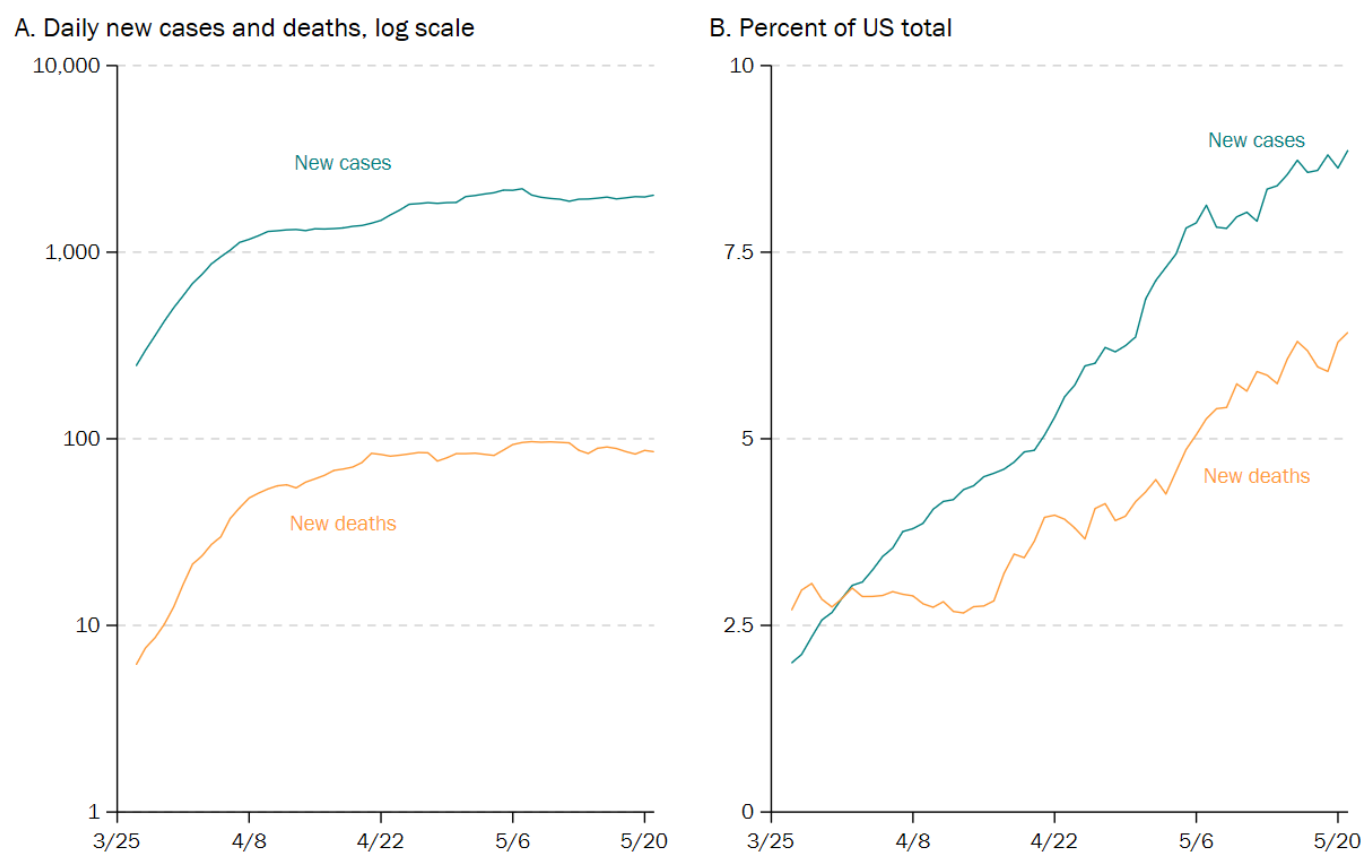

Figure 2. New COVID cases and deaths in rural counties, by date. Counties $>50 \%$ rural. Seven-day trailing averages

areas), the South and Mid-Atlantic (from Louisiana to Maryland), Michigan, and New England. The upper Midwest and West have much lower numbers of rural cases. Panel B shows the same case count expressed in terms of cases per 1,000 population. This shows that the Mid-Atlantic, Michigan, and New England rural counties, although reporting many cases, do not have the highest rates per capita. The per capita map isolates counties in the Southwest, South, and Midwest that, as we will see, are sites outbreaks in prisons, meat or poultry processing plants, or nursing homes.

It is not surprising that rural counties are underrepresented in reported COVID-19 case and death rates, because community transmission of the disease was first identified in coastal urban areas where people had traveled from Europe and China (Zimmer, 2020). Not only were rural counties less likely to host the initial vectors of the disease, they also have lower population density and fewer face-to-face interactions, offering less opportunity for viral transmission. However, once establishing a foothold in some rural areas, the virus has spread robustly and their share of the epidemic has increased.

Figure 2 shows the number of new cases and deaths reported each day in rural counties, from the last week of March to mid-May, on a log scale (panel A), and the share of new cases and deaths each day that are in rural areas (panel B). Both panels present the data smoothed using seven-day trailing averages. As the epidemic slowed in much of the country in early May, including major metropolitan areas such as New York and Detroit (Bosman et al., 2020a), the pace of new reports of cases and deaths in rural areas did not slow, at more than 2,000 and just under 100 per day respectively. New cases and deaths in rural counties, as a share of the U.S. total, increased substantially over this period.
The dynamics of rural transmission are naturally different from those in urban areas, where there is more face-to-face interaction, denser housing, larger institutions, mass transportation, and larger social events. With a similar level of initial infection, transmission occurs more efficiently in areas of denser population (Rocklöv and Sjödin, 2020.). To explore differences in transmission patterns between rural and urban areas, Figure 3 presents the relationship between COVID-19 cases per capita and population density (residents per 100 square miles), with both measures logged and including only those counties with any reported cases. The overall slope (weighted by population) is .35. However, the slope is steeper among urban (.37) than among rural (.20) counties (the slopes, and the difference between, them are highly significant statistically). Although only suggestive, this distinction might imply that rural outbreaks of the epidemic are more driven by idiosyncratic circumstances (such as the presence of a prison, meat plant, or nursing home); while transmission in urban outbreaks is generated by interactions across a wider set of social settings, determined in greater part by the level population density.

Rather than relying on overall population density to achieve viral transmission, in rural areas it appears the novel coronavirus spreads most successfully through pockets of dense and vulnerable populations within confined institutional settings. A prison in a rural area gains none of the protections of looser population concentration that benefit the wider community. Figure 4 shows the growth of outbreaks, by county, associated with the three types of institutions described above: prisons, meat and poultry processing plants, and nursing homes. ${ }^{3}$ (Again, the categorization of these outbreaks is drawn from my reading of local and national news

\footnotetext{
${ }^{3}$ I include with nursing homes one outbreak, in East Feliciana, LA, apparently associated with a state mental hospital.
} 


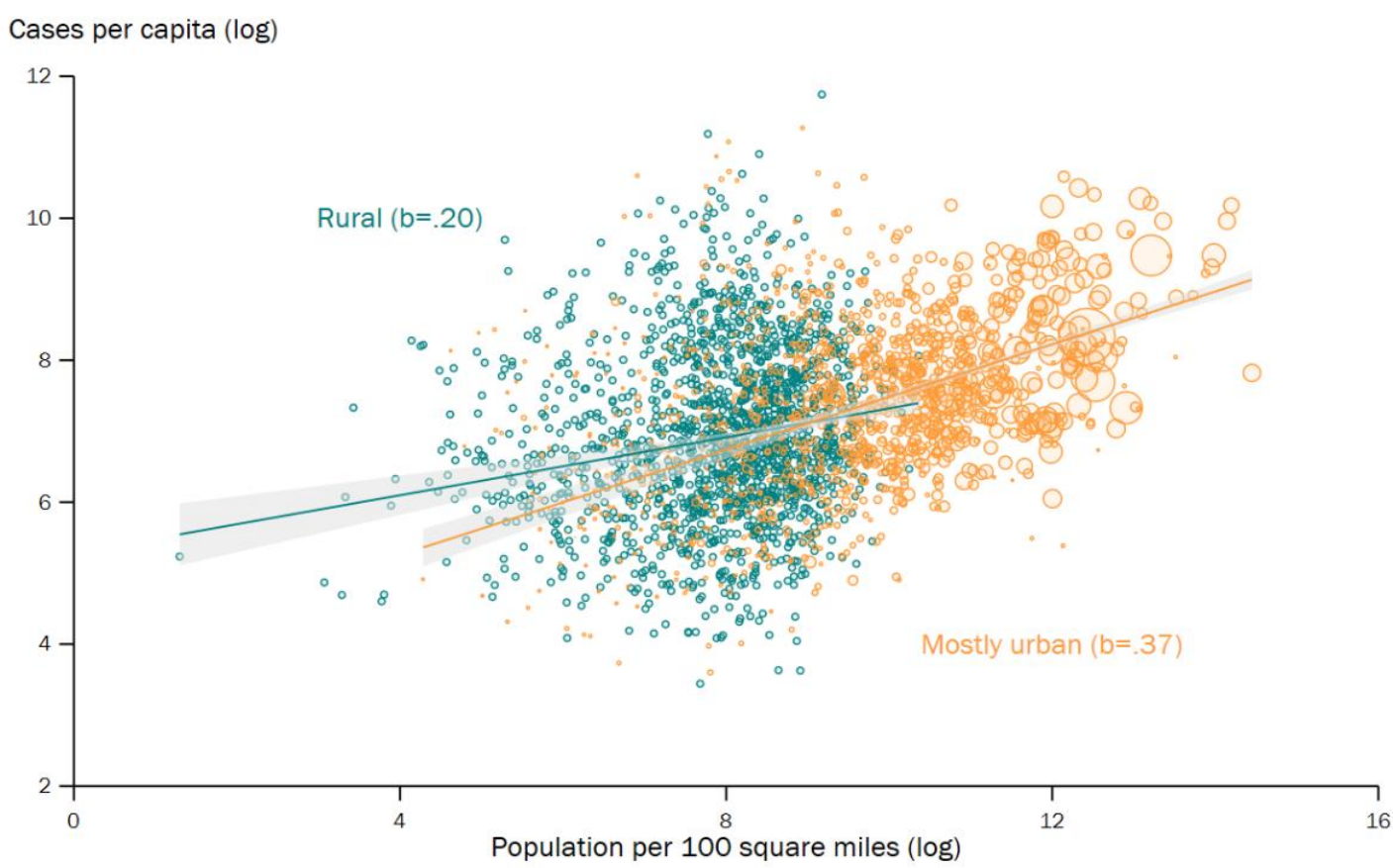

Figure 3. Population density and cumulative COVID cases, rural and urban counties. Rural counties are $>50 \%$ rural; includes counties with any cases. Urban markers are scaled by population. Regression lines are population-weighted; with $95 \%$ confidence intervals. Data for May 21, 2020
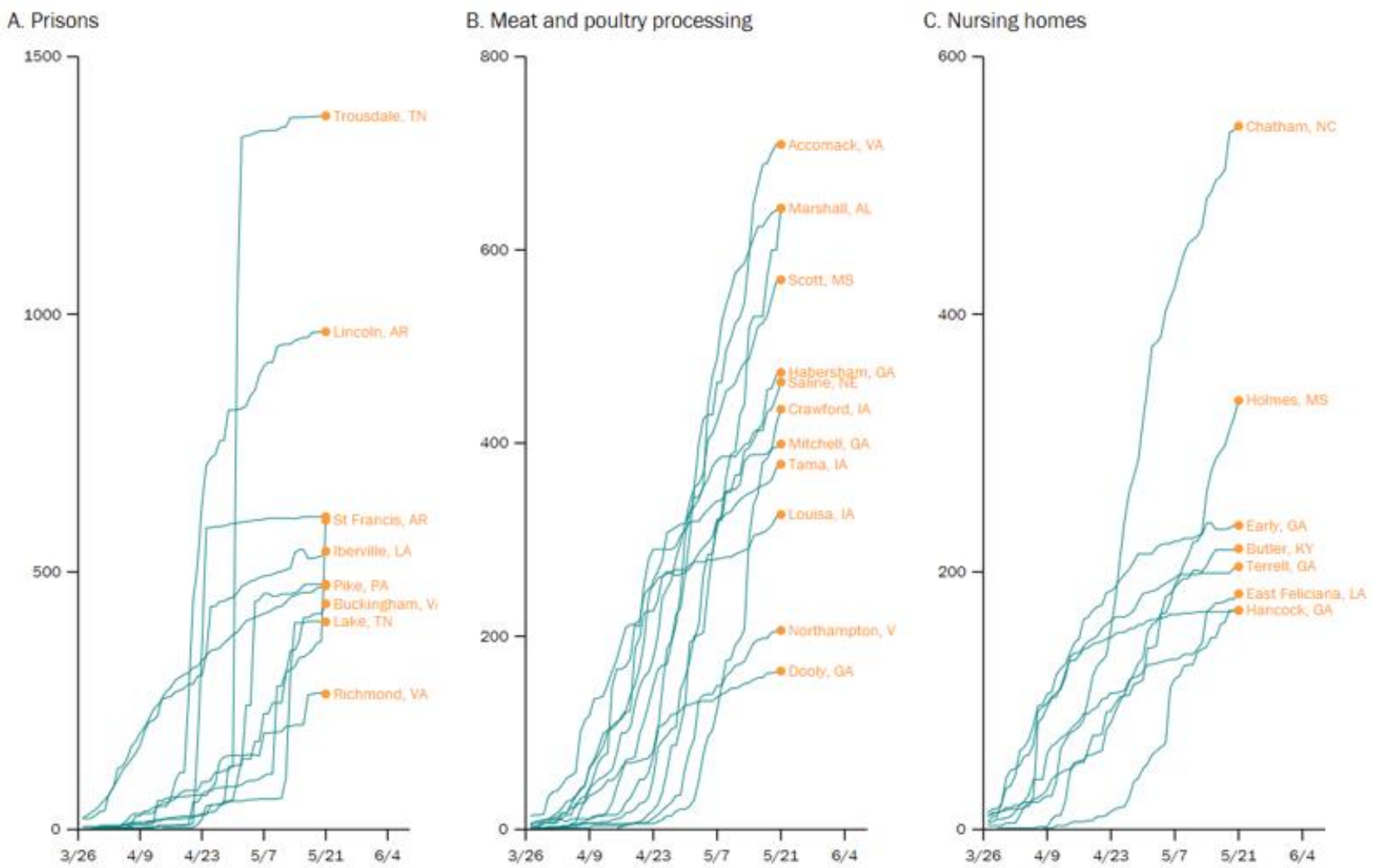

Figure 4. COVID-19 cases in selected rural counties, by date. Counties >50\% rural. Data as of May 21, 2020

reports or public health authorities, and may not be definitive.) Of these, counties with prison outbreaks (panel A) report the greatest number of cases (note the y-axis scales differ across panels). ${ }^{4}$ The prison-involved counties also demonstrate a disturbing pattern of suddenly reporting hundreds of cases at once, which implies their testing regimes or reporting practices are not adequately capturing the true pattern of infection. Although not a comprehensive accounting of rural

${ }^{4}$ Outbreaks in the counties listed are all associated with state prisons, except Pike, PA, which involves an ICE detention facility. 
Table 2. COVID-19 outbreaks in selected rural counties

\begin{tabular}{|c|c|c|c|c|c|c|c|c|c|}
\hline County & State & Population & $\begin{array}{c}\text { Percent } \\
\text { rural }\end{array}$ & Cases & $\begin{array}{c}\text { Cases per } \\
1,000\end{array}$ & Deaths & $\begin{array}{c}\text { Percent } \\
\text { Black }\end{array}$ & $\begin{array}{c}\text { Percent } \\
\text { Hispanic }\end{array}$ & Note \\
\hline Trousdale & TN & 11,012 & 100 & 1,385 & 125.8 & 4 & 11.5 & 2.4 & State prison \\
\hline Lincoln & $\mathrm{AR}$ & 13,383 & 100 & 966 & 72.2 & 8 & 30.4 & 3.9 & State prison \\
\hline Accomack & VA & 32,412 & 100 & 709 & 21.9 & 11 & 28.6 & 9.3 & Tyson poultry \\
\hline Marshall & $\mathrm{AL}$ & 96,109 & 53 & 643 & 6.7 & 9 & 3.0 & 14.3 & Chicken \\
\hline Robeson & $\mathrm{NC}$ & 131,831 & 63 & 643 & 4.9 & 13 & 23.8 & 9.0 & Poultry \\
\hline Bledsoe & $\mathrm{TN}$ & 14,755 & 100 & 607 & 41.1 & 1 & 7.1 & 2.5 & State prison \\
\hline St Francis & $\mathrm{AR}$ & 25,439 & 52 & 600 & 23.6 & 0 & 52.9 & 5.4 & Federal prison \\
\hline Scott & MS & 28,287 & 72 & 569 & 20.1 & 10 & 38.4 & 11.5 & Chicken \\
\hline Chatham & $\mathrm{NC}$ & 73,139 & 66 & 546 & 7.5 & 25 & 12.7 & 12.3 & Nursing home \\
\hline Iberville & LA & 32,721 & 59 & 540 & 16.5 & 39 & 48.8 & 2.7 & State prisons \\
\hline Muhlenberg & $\mathrm{KY}$ & 30,774 & 68 & 476 & 15.5 & 7 & 4.9 & 1.5 & State prison \\
\hline Habersham & GA & 45,388 & 59 & 473 & 10.4 & 18 & 4.1 & 15.1 & Chicken \\
\hline Pike & PA & 55,933 & 71 & 473 & 8.5 & 18 & 6.5 & 11.4 & ICE detention \\
\hline Saline & $\mathrm{NE}$ & 14,350 & 51 & 463 & 32.3 & 1 & 1.6 & 25.9 & Smithfield pork \\
\hline Buckingham & VA & 16,999 & 100 & 438 & 25.8 & 2 & 33.9 & 2.5 & State prison \\
\hline Crawford & IA & 17,158 & 52 & 435 & 25.4 & 2 & 3.9 & 28.5 & Multiple meat \\
\hline Lake & $\mathrm{TN}$ & 7,411 & 100 & 403 & 54.4 & 0 & 28.7 & 2.4 & State prison \\
\hline Mitchell & GA & 22,192 & 55 & 399 & 18.0 & 32 & 48.1 & 4.6 & Tyson chicken \\
\hline Tama & IA & 16,904 & 72 & 378 & 22.4 & 23 & 1.0 & 10.3 & Iowa Premium beef \\
\hline Holmes & MS & 17,622 & 87 & 333 & 18.9 & 21 & 82.5 & 1.1 & Nursing home \\
\hline Louisa & IA & 11,169 & 100 & 326 & 29.2 & 6 & 1.1 & 16.2 & Tysons pork \\
\hline Richmond & VA & 9,038 & 100 & 263 & 29.1 & 4 & 29.8 & 7.2 & State prison \\
\hline Early & GA & 10,247 & 66 & 236 & 23.0 & 29 & 51.4 & 2.3 & Nursing home \\
\hline Butler & $\mathrm{KY}$ & 12,772 & 100 & 218 & 17.1 & 6 & 0.6 & 3.5 & Nursing home \\
\hline Northampton & VA & 11,735 & 100 & 206 & 17.6 & 16 & 33.9 & 9.3 & Poultry plants \\
\hline Terrell & GA & 8,611 & 51 & 204 & 23.7 & 25 & 60.4 & 2.7 & Nursing home \\
\hline East Feliciana & LA & 19,305 & 100 & 183 & 9.5 & 27 & 42.9 & 1.7 & State hospital \\
\hline Hancock & GA & 8,348 & 62 & 170 & 20.4 & 15 & 71.2 & 2.4 & Nursing home \\
\hline Randolph & GA & 6,833 & 51 & 170 & 24.9 & 21 & 61.5 & 2.3 & Nursing home \\
\hline Dooly & GA & 13,706 & 54 & 164 & 12 & 12 & 50.0 & 6.9 & Tyson chicken \\
\hline
\end{tabular}

Data as of May 21, 2020

outbreaks, the 30 counties shown in Figure 4, and listed in Table 2, together account for 15 percent of all reported rural cases, and represent the largest rural outbreaks, with the exception of those around the Navajo, Zuni, Hopi, and Fort Apache reservations, which account for an additional 4,064 cases.

Finally, I present rural COVID-19 outbreaks according to the race/ethnic composition of their counties. This makes clear that some of the outbreak counties describe above are outliers not only with regard to their number of cases, but also with regard to high minority population concentration. Figure 5 shows rural counties and their COVID-19 case counts by population percent Hispanic (panel A), American Indian (B), and Black (C), with select counties labeled for exposition. The overall relationship between case count and percent minority is strongest for Black population (not shown), but in all three cases there are clear outlier cases comprising severe rural outbreaks in counties with disproportionate minority populations.

\section{DISCUSSION}

At this writing, rural U.S. counties account for less of the COVID-19 outbreak than their share of the population, reflecting the epidemic's initial explosion in coastal urban areas and the greater propensity for transmission in places with greater population density. However, the share of cases and deaths in rural counties is rising, apparently driven by outbreaks concentrated in institutional settings conducive to transmission: prisons, meat and poultry processing facilities, and nursing homes. In addition to the institutional factors, the impact of the epidemic in rural areas may be heightening due to their weaker health infrastructure and more vulnerable populations, especially due to age, socioeconomic status, and health conditions. As a result, the epidemic may contribute to the ongoing decline of health, economic, and social conditions in rural areas (Ajilore, 2020).

There are several notable weaknesses to this analysis. First, it relies on officially reported COVID-19 cases and deaths, which are dependent on laboratory testing and subject to underreporting (Lipsitch et al., 2020). People who administer institutions such as prisons, factories, and nursing homes are often motivated to downplay the severity of their outbreaks, even if they have the resources necessary to track them. Second, my notes on selected county cases are not a substitute for more systematic analysis. Subsequent analysis may examine the association of cases with the presence of these institutions more systematically, using databases of their locations. Finally, more systematic analysis will require consideration of all-cause mortality, which allow a more holistic assessment of the full impact of COVID-19's epidemic in rural counties (Goldstein and Lee, 2020). 

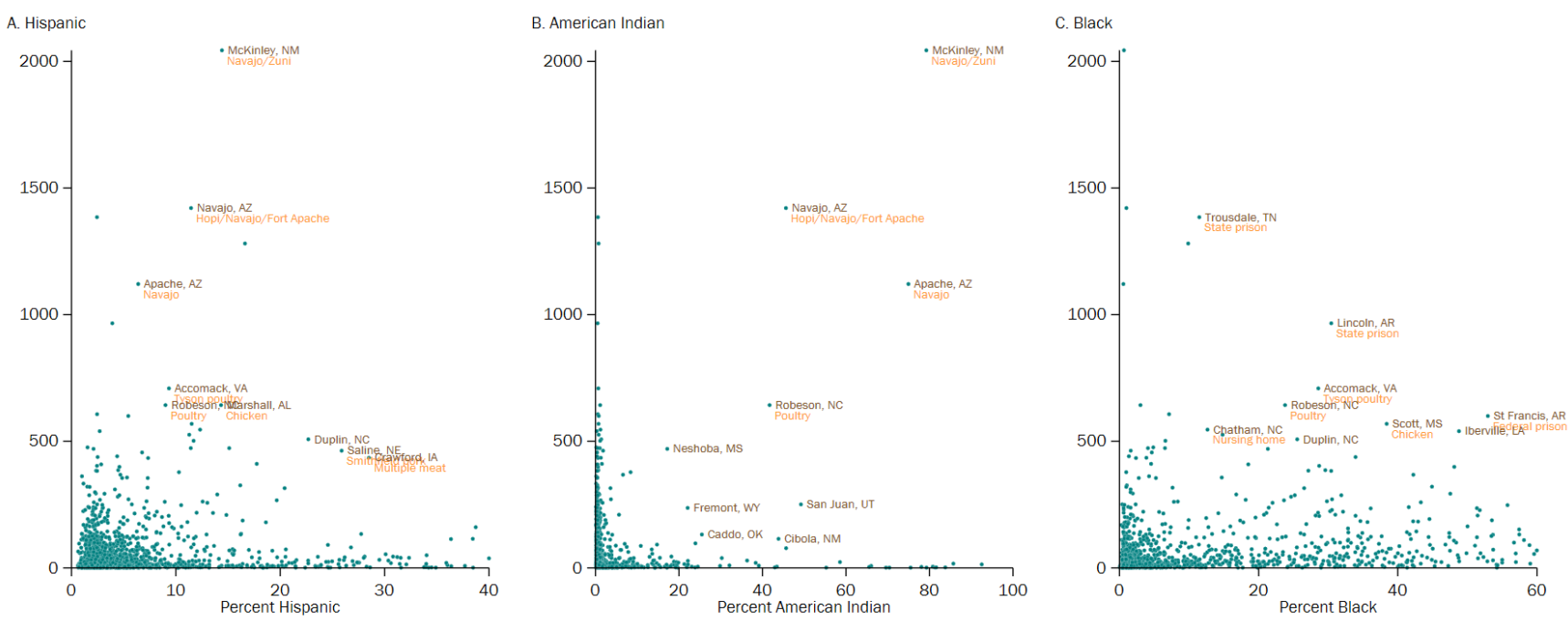

Figure 5. COVID-19 cases and minority composition in selected rural counties. Counties $>50 \%$ rural. Black and American Indian are single-race counts. Counties with more than 40\% Hispanic population not shown. Data as of May 21, 2020

\section{REFERENCES}

Ajilore, O. (2020). The Coronavirus May Accelerate the Demise of Rural America [WWW Document]. InsideSources. Available at: https://www.insidesources.com/the-corona virus-may-accelerate-the-demise-of-rural-america/ (Accessed: May 17, 2020).

Almagro, M. and Orane-Hutchinson, A. (2020). The Determinants of the Differential Exposure to COVID-19 in New York City and Their Evolution Over Time (SSRN Scholarly Paper No. ID 3573619). Social Science Research Network, Rochester, NY. https://doi.org/10.2139/ ssrn.3573619

Ameh, G. G., Njoku, A., Inungu, J. and Younis, M. (2020). Rural America and Coronavirus Epidemic: Challenges and Solutions. European Journal of Environment and Public Health, 4(2), em0040. https://doi.org/10.29333/ejeph/8200

Bosman, J., Harmon, A. and Smith, M. (2020a). Coronavirus Cases Slow in U.S., but the Big Picture Remains Tenuous. N. Y. Times.

Bosman, J., Smith, M. and Harmon, A. (2020b). With New Hot Spots Emerging, No Sign of a Respite. N. Y. Times.

Cafer, A. and Rosenthal, M. (2020). COVID-19 in the Rural South: A Perfect Storm of Disease, Health Access, and CoMorbidity. APCRL Policy Briefs.

Carson, J. (2020). Rural Areas with Seasonal Homes Hit Hard by COVID-19. Carsey Sch. Public Policy Sch. Repos. https://doi.org/10.34051/p/2020.391

CDC, 2020. Coronavirus Disease 2019 (COVID-19) in the U.S. [WWW Document]. Cent. Dis. Control Prev. Available at: https://www.cdc.gov/coronavirus/2019-ncov/casesupdates/cases-in-us.html (Accessed: May 16, 2020).

Chen, X., Orom, H., Hay, J. L., Waters, E. A., Schofield, E., Li, Y. and Kiviniemi, M. T. (2019). Differences in Rural and Urban Health Information Access and Use. J. Rural Health 35, 405-417. https://doi.org/10.1111/jrh.12335
Dorn, A. van, Cooney, R. E. and Sabin, M. L. (2020). COVID-19 exacerbating inequalities in the US. The Lancet 395, 12431244. https://doi.org/10.1016/S0140-6736(20)30893-X

Dyal, J. W. (2020). COVID-19 Among Workers in Meat and Poultry Processing Facilities - 19 States, April 2020. MMWR Morb. Mortal. Wkly. Rep. 69. https://doi.org/10.15585/mmwr.mm6918e3

Dyer, O. (2020). Covid-19: Black people and other minorities are hardest hit in US. BMJ 369. https://doi.org/10.1136/bmj.m1483

Goldstein, J. R. and Lee, R. D. (2020). Demographic Perspectives on Mortality of Covid-19 and Other Epidemics (Working Paper No. 27043), Working Paper Series. National Bureau of Economic Research. https://doi.org/10.3386/w27043

Greenberg, A. J., Haney, D., Blake, K. D., Moser, R. P. and Hesse, B. W. (2018). Differences in Access to and Use of Electronic Personal Health Information Between Rural and Urban Residents in the United States. J. Rural Health, 34, S30-S38. https://doi.org/10.1111/jrh.12228

Into America (2020). Transcript: Into Tracking Coronavirus in Nursing Homes [WWW Document]. NBC News. Available at: https://www.nbcnews.com/podcast/into-america/trans cript-tracking-coronavirus-nursing-homes-n1207916 (Accessed: May 16, 2020).

James, C. V., Moonesinghe, R., Wilson-Frederick, S. M., Hall, J. E., Penman-Aguilar, A. and Bouye, K. (2017). Racial/Ethnic Health Disparities Among Rural Adults - United States, 2012-2015. Mmwr Surveill. Summ. 66, 1-9.

James, W. and Cossman, J. S. (2017). Long-Term Trends in Black and White Mortality in the Rural United States: Evidence of a Race-Specific Rural Mortality Penalty. J. Rural Health, 33, 21-31. https://doi.org/10.1111/jrh.12181

Kovich, H. (2020). Rural Matters - Coronavirus and the Navajo Nation. N. Engl. J. Med. O. https://doi.org/10.1056/ NEJMp2012114 
Laughland, O. and Holpuch, A. (2020). "We're modern slaves": How meat plant workers became the new frontline in Covid-19 war. The Guardian.

New York Times (2020). nytimes/covid-19-data. The New York Times.

Ratcliffe, M., Burd, C., Holder, K. and Fields, A. (2016). Defining Rural at the U.S. Census Bureau (No. ACSGEO-1). U.S. Census Bureau, Washington, DC.

Rocklöv, J. and Sjödin, H. (n.d.). High population densities catalyse the spread of COVID-19. J. Travel Med. https://doi.org/10.1093/jtm/taaa038

Singh, G. K., Kogan, M. D. and Slifkin, R. T. (2017). Widening Disparities In Infant Mortality And Life Expectancy Between Appalachia And The Rest Of The United States, 1990-2013. Health Aff. (Millwood) 36, 1423-1432. https://doi.org/10.1377/hlthaff.2016.1571

Solis, J., Franco-Paredes, C., Henao-Martínez, A. F., Krsak, M. and Zimmer, S. M. (2020). Structural Vulnerability in the United States Revealed in Three Waves of Novel Coronavirus Disease (COVID-19) tpmd200391. https://doi.org/10.4269/ajtmh.20-0391

UFCW (2020). Trump Order to Keep Meatpacking Plants Open Must Include Immediate Action to Strengthen Coronavirus Testing and Safety Measures. Available at: http://www.ufcw.org/2020/04/28/order/ (Accessed: May $16,2020)$.
U.S. Census Bureau (2020). County Population by Characteristics: 2010-2018 [WWW Document]. U. S. Census Bur. Available at: https://www.census.gov/data/tables/ time-series/demo/popest/2010s-counties-detail.html (Accessed: May 16, 2020).

U.S. Census Bureau (2019). USA Counties: 2011 [WWW Document]. $U$. S. Census Bur. Available at: https://www.census.gov/library/publications/2011/compe ndia/usa-counties-2011.html (Accessed: May 16, 2020).

Wallace, M. (2020). COVID-19 in Correctional and Detention Facilities - United States, February-April 2020. MMWR Morb. Mortal. Wkly. Rep. 69. https://doi.org/10.15585/mmwr.mm6919e1

White House, T. (2020). President Donald J. Trump Is Taking Action to Ensure the Safety of Our Nation's Food Supply Chain [WWW Document]. White House. Available at: https://www.whitehouse.gov/briefings-statements/ president-donald-j-trump-taking-action-ensure-safetynations-food-supply-chain/ (Accessed: May 16, 2020).

Zimmer, C. (2020). Most New York Coronavirus Cases Came from Europe, Genomes Show. N. Y. Times. 